\title{
PERANCANGAN SISTEM INFORMASI PARIWISATA DAN KEBUDAYAAN KABUPATEN MAYBRAT BERBASIS WEB (STUDI KASUS : KOMUNITAS PECINTA ALAM PAPUA BARAT)
}

\section{Design Of Web-Based Tourism And Culture Information System Of Maybrat District (A Case Study in West Papua Nature-Lovers Community)}

\author{
Melda Agnes Manuhutu ${ }^{1}$, Yulianti Flasao ${ }^{2}$, dan Lulu Jola Uktolseja ${ }^{3}$ \\ ${ }^{1,2}$ Jurusan Sistem Informasi, Fakultas Ilmu Komputer, Universitas Victory Sorong \\ ${ }^{3}$ Jurusan Pendidikan Bahasa Inggris, Fakultas Keguruan dan Ilmu Pendidikan, Universitas Victory Sorong \\ Institusi; Jl. Basuki Rahmat, KM. 11.5, Kelurahan Klawuyuk, Sorong, Papua Barat \\ e-mail: ${ }^{1}$ melda.a.manuhutu@gmail.com
}

Received 15 / 11 / 2018, Revised 18 / 11 / 2018, Accepted 25 / 11 / 2018

\begin{abstract}
Accompanied by the development of information technology, communication technology has developed rapidly. One sector that is developing in the field of tourism which contributes to more interactive information through the internet. Where Maybrat Regency has considerable tourism and cultural potential, it is managed by the Maybrat Regency Tourism and Culture Community which is very useful if managed well and effectively. This is to improve the economy of the community, the quality of human resources, through tourism assistance that enables increased regional pride. Accurate presentation of the area that can be used to increase revenue in the region itself. Now there is not enough information about tourist objects in Maybrat Regency so that not many tourists and people know the potential of tourism objects. The system development model used is the prototype model. By building interfaces using Adobe Dreamweaver CS6. The database is stored using php and displayed via XAMMP. This system is also built on the framework of a system that is a code igniter.
\end{abstract}

keywords - System, Information, Tourism, Culture, Website

\section{Pendahuluan}

Papua Barat sebagai bagian dari Wilayah Indonesia, memiliki begitu banyak obyek wisata dan budaya yang begitu indah. Namun, saat ini obyek wisata dan budaya tersebut belum begitu diketahui banyak masyarakat karena belum banyaknya informasi yang diberikan. Efektifitas dan efisiensi teknologi informasi saat ini berkembang luas dan pesat sehingga menjadikan teknologi informasi begitu diminati saat ini. Teknologi informasi adalah kumpulan sumber daya informasi para penggunanya dan memanajemen yang menjalankannya yang digunakan untuk mengolah data, termasuk memproses, mendapatkan, menyusun, menyimpan, memanipulasi data dalam berbagai cara untuk menghasilkan informasi yang berkualitas, yaitu informasi yang relevan, akurat dan tepat waktu, yang digunakan untuk keperluan pribadi, bisnis, dan pemerintahan dan merupakan informasi yang strategis untuk pengambilan keputusan.

Teknologi ini menggunakan seperangkat komputer untuk mengolah data, sistem jaringan untuk menghubungkan satu komputer dengan komputer yang lainnya sesuai dengan kebutuhan, 
dan teknologi telekomunikasi digunakan agar data dapat disebar dan diakses secara global. Diiringi perkembangan teknologi informasi, teknologi komunikasi juga ikut berkembang secara pesat. Salah satu sektor yang berkembang dalam perkembangan teknologi adalah di bidang pariwisata yang memberikan andil untuk mendistribusikan informasi objek-objek wisata yang lebih interaktif khususnya melalui teknologi internet. Dimana Kabupaten Maybrat ini memiliki potensi pariwisata dan kebudayaan yang begitu besar. Terdapat obyek wisata Danau, Sungai, Gunung, serta obyek budaya seperti tarian dan lagu yang begitu banyak. Aset wisata dan budaya ini, apabila dikelola/dikemas secara baik dipastikan akan dapat memberikan efek bagi peningkatan ekonomi masyarakat, peningkatan kualitas sumber daya manusia, melalui proses kunjungan wisatawan dapat meningkatnya prestasi kebanggaan daerah yang dihasilkan.

Penyajian data yang akurat tentang keberadaan daerah wisata sangat diperlukan untuk mendukung pengembangan potensi pada daerah Kabupaten Maybrat yang disajikan dapat diandalkan untuk meningkatkan pendapatan di daerah Kabupaten itu sendiri. Namun saat ini belum adanya informasi yang cukup memadai tentang objek-objek wisata yang ada di Kabupaten Maybrat sehingga belum banyak wisatawan dan juga masyarakat yang mengetahui objek-objek wisata yang cukup potensial.

Berdasarkan hal tersebut, maka penulis tertarik untuk merancang sebuah sistem informasi untuk menjawab permasalahan yang ada dan menuangkannya pada penelitian yang berjudul "Perancangan Sistem Informasi Pariwisata dan Kebudayaan Kabupaten Maybrat Berbasis Web (Komunitas Pecinta Alam)".

\section{Landasan Teori}

\subsection{Definisi Sistem Informasi}

Sistem informasi adalah mengkoleksi, menyimpan, memproses, menganalisa, dan menyebarkan informasi untuk tujuan khusus [1]. Sistem informasi merupakan sebuah sistem yang dapat mengatur kombinasi dari orang-orang, perangkat lunak, perangkat kelas, jaringan komunikasi dan sumber daya yang mengumpulkan, mengubah, dan menyebarkan informasi di dalam organisasi [2]. Dari kedua kutipan tersebut, dapat disimpulkan bahwa sistem informasi adalah sekumpulan elemen yang saling berhubungan untuk menyelesaikan suatu sasaran dalam sebuah organisasi [3-5].

\subsection{Perangkat Sistem Informasi}

Sebuah sistem informasi yang lengkap memiliki kelengkapan sistem seperti hardware, software, data, process dan brainware [6]. Sistem informasi memiliki komponen yang saling terintegrasi membentuk satu kesatuan dalam mencapai sasaran sistem adalah Blok Masukan (Input Block), Blok Model (Model Block), Blok Keluaran (Output Block), Blok Teknologi (Technology Block), Blok Basis Data (Database Block) dan Blok Kendali (Control Block) [6].

\subsection{Komputer}

Komputer adalah peralatan yang menerima data dan menyimpan kemudian diproses untuk menghasilkan data dalam bentuk lain. Dari pengertian diatas penulis menyimpulkan Komputer adalah sebuah mesin yang dapat menerima input, mengolah data dan menghasilkan output yang dikehendaki [7]. 


\subsection{Penelitian Terdahulu}

Penelitian terdahulu sangat penting sebagai dasar pijakan dalam rangka penyusunan penelitian ini. Kegunaanya untuk mengetahui hasil yang telah dilakukan oleh peneliti terdahulu. Penelitian yang berkaitan dengan Sistem Informasi Pariwisata dan Kebudayaan berbasis website ditemukan pada beberapa penelitian berikut. Penelitian dengan Judul "Sistem Informasi Pariwisata Pantai Berbasis Web pada Dinas Pariwisata dan Ekonomi Kreatif Kabupaten Banggai Kepulauan”. Penelitian ini membangun sistem informasi berbasis web yang dapat mengelola dan menyebarkan informasi pariwisata pantai yang ada di Kab. Banggai Kepulauan. Penelitian ini merupakan penelitian deskriptif kualitatif dengan pendekatan rekayasa perangkat lunak. Metode pengembangan sistem yang digunakan adalah waterfall modelling. Hasil penelitian ini menyimpulkan sistem informasi pariwisata pantai berbasis web dapat mengelola data-data pariwisata yang ada secara efektif dan efisien serta dapat diakses dengan cepat dan mudah untuk memberikan informasi tentang pariwisata pantai yang ada di Kab. Banggai Kepulauan. Untuk itu kedepan Dinas Pariwisata dan Ekonomi Kreatif Kab. Banggai Kepulauan harus selalu memperbaharui database yang ada dengan informasi perkembangan pariwisata terbaru dan melengkapi aplikasi ini sesuai perkembangan teknologi dengan menambah fungsi-fungsi yang lebih lengkap sesuai dengan kebutuhan masyarakat [8].

Penelitian dengan Judul "Analisis dan Perancangan Sistem Informasi Pariwisata Berbasis Web sebagai Media Promosi pada Kabupaten Tebo". Metode penelitian yang dilakukan adalah dengan pengumpulan data melalui studi literatur, wawancara, dan observasi, serta menganalisa kebutuhan perangkat lunak, membangun database dengan mysql, merancang antar muka menggunakan Macromedia Dreamweaver dan PHP, melakukan pengujian program sebagai tahap akhir dalam pembuatan sistem informasi pariwisata berbasis web. Hasil perancangan berupa sitem informasi pariwisata berbasis web yang diharapkan mampu menjadi sebuah media yang dapat mempromosikan wisata Kabupaten tebo selanjutnya dengan adanya perancangan desain web ini diharapkan adanya proses perancangan serupa untuk menghasilkan karya yang lebih baik dan lebih lengkap dari karya yang ada [9].

Berdasarkan ketiga penelitian tersebut, peneliti dapat menarik kesimpulan bahwa ketiga penelitian tersebut memiliki tujuan yang sama dengan penelitian ini yaitu merancang sebuah sistem informasi berbasis website. Adapun perbedaan dengan penelitian yang saat ini sedang dilakukan oleh penulis yaitu terdapat perbedaan penggunaan tool seperti penelitian terdahulu tersebut menggunakan Macromedia Dreamweaver sedangkan penelitian ini menggunakan Adobe Dreamweaver yang tentu lebih baik dari segi fungsi yang ditawarkan. Penelitian ini juga menggunakan code igniter sebagai framework sehingga tampilan yang dibangun juga lebih menarik dan responsif.

\section{Metode Penelitian}

\subsection{Metode Penelitian}

Secara garis besar, lingkup penelitian sistem informasi meliputi pengembangan, penggunaan dan aplikasi sistem informasi oleh individu, organisasi dan masyarakat [10]. Metode penelitian dalam sistem informasi lebih dikenal dengan nama model pengembangan sistem. Di mana model pengembangan sistem tersebut digunakan atau dipilih sesuai dengan kebutuhan pada sistem yang akan dirancang atau dibangun. Model pengembangan sistem yang digunakan dalam penelirian ini 
adalah model protorype. Dengan metode prototyping ini akan dihasilkan prototype sistem sebagai perantara pengembang dan pengguna agar dapat berinteraksi dalam proses kegiatan pengembangan sistem informasi [11]. Serta teknik pengumpulan data yang digunakan adalah observasi dan wawancara. Tahapan-tahapan dalam Prototyping pada penelitian ini adalah sebagai berikut:

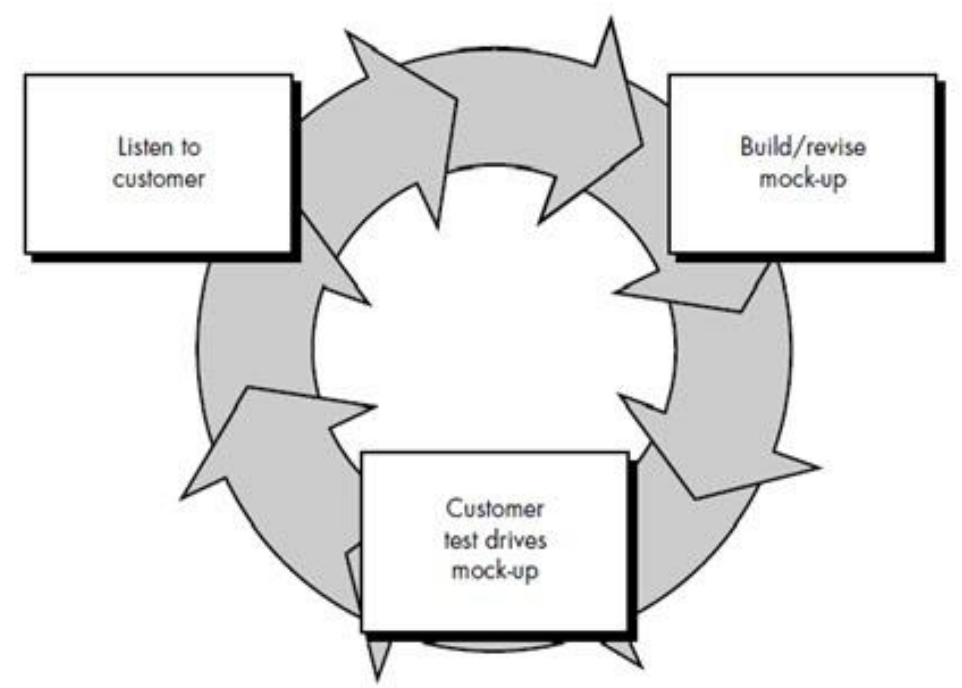

Gambar 1. Model Prototype

\subsubsection{Listen to the Customer}

1. Pengumpulan Kebutuhan

Pelanggan dan pengembang bersama-sama mendefinisikan format seluruh perangkat lunak, mengidentifikasikan semua kebutuhan, dan garis besar sistem yang akan dibuat. Dalam tahapan ini, pengembang melakukan observasi dan wawancara dengan salah satu pegawai pada Dinas Pariwisata dan Kebudayaan Kabupaten Maybrat, kemudian dengan beberapa pecinta wisata dan budaya.

\subsubsection{Build/Revise Mock-Up}

\section{Membangun Prototyping.}

Membangun prototyping dengan membuat perancangan sementara yang berfokus pada penyajian kepada pengguna.

2. Evaluasi Protoptyping.

Evaluasi ini dilakukan oleh pelanggan apakah prototyping yang sudah dibangun sudah sesuai dengan keinginann pelanggan. Jika sudah sesuai maka langkah 4 akandiambil. Jika tidak prototyping direvisi dengan mengulangu langkah 1, 2, dan 3 .

\section{Mengkodekan System.}

Dalam tahap ini prototyping yang sudah di sepakati diterjemahkan ke dalam bahasa pemrograman yang sesuai. 


\subsubsection{Customer Test Drive and Mock--Up}

1. Menguji system.

Setelah sistem sudah menjadi suatu perangkat lunak yang siap pakai, harus dites dahulu sebelum digunakan. Pengujian dalam penelitian ini yaitu Black box testing.

2. Evaluasi Sistem.

Pelanggan mengevaluasi apakah sistem yang sudah jadi sudah sesuai dengan yang diharapkan. Juka ya, langkah 7 dilakukan; jika tidak, ulangi langkah 4 dan

3. Menggunakan system.

Perangkat lunak yang telah diuji dan diterima pelanggan siap untuk digunakan.

Dalam memperoleh bahan pendukung yang sangat berguna bagi penulis untuk mencari atau mengumpulkan data yang diperlukan dalam penelitian ini, penulis menggunakan beberapa cara yaitu:

\section{Pengamatan (observation)}

Kegiatan observasi ini dilakukan dengan melakukan pengamatan langsung terhadap objek yang akan diteliti guna mengetahui secara langsung mengenai Sistem Informasi Pariwisata ini

\section{Wawancara (Interview)}

Penulis melakukan penelitian lapangan dengan cara melakukan wawancara kepada pihak yang berkaitan untuk memperoleh data-data yang dibutuhkan oleh penulis. Hal ini dilakukan agar penulis mengetahui kegiatan apa saja yang dilakukan, serta untuk memperoleh data yang akurat serta relevan agar dapat menghasilkan suatu rancangan website yang sesuai kebutuhan.

\subsection{Analisis Kebutuhan Sistem}

Analisis kebutuhan sistem merupakan tahap yang penting dalam mengembangkan suatu sistem. Berikut penjelasan dari fungsi masing-masing pengguna sistem:

1) Admin
a. Admin melakukan login sistem.
b. Admin mengelola data website antara lain profil, berita, pelayanan, dan agenda.
c. Admin dapat melakukan tambah, ubah dan hapus pada kolom akses kelola bagi admin.
d. Admin melakukan logout sistem ketika proses kerja telah selesai dilakukan.

2) Pengunjung Sistem 

a. Pengguna membuka halaman website.
b. Pengguna melihat profil, berita, pelayanan dan agenda pada website.

\subsection{Analisa Desain Sistem}

Desain sistem merupakan kegiatan yang lakukan untuk mendesain suatu sistem yang mempunyai tahapan-tahapan kerja yang tersusun secara logis, yang dimulai dari tahap pengumpulan data-data dan kebutuhan sistem yang akan dibangun, tahap perancangan sistem berdasarkan data-data dan kebutuhan yang telah dikumpulkan, hingga sistem yang diinginkan atau dibutuhkan selesai dibangun dan siap untuk digunakan. Adapun desain sistem informasi ini adalah sebagai berikut:

\subsubsection{Flowchart Sistem yang Diusulkan}

Gambar 2 menampilkan alur sistem (flowchart) sistem informasi Pariwisata dan Kebudayaan ini. Ketika memulai membuka sistem, admin harus melakukan login dengan memasukkan username dan password yang tepat. Setelah memasukkan kedua item tersebut, maka proses login akan dimulai dengan memeriksa database, apabila terjadi ketidakcocokkan username dan password maka proses login gagal dan sistem akan membuka kembali halaman awal login. Namun jika username dan password yang dimasukkan tepat atau valid, maka sistem yaitu halaman kerja admin akan terbuka. Pada halaman kelola admin tersebut, terdapat beberapa data yang dapat dikelola diantaranya kelola profil, berita, agenda dan pelayanan. Apabila proses data yang dikelola lengkap, admin dapat menyimpan data dan logout sebagai tanda selesai.

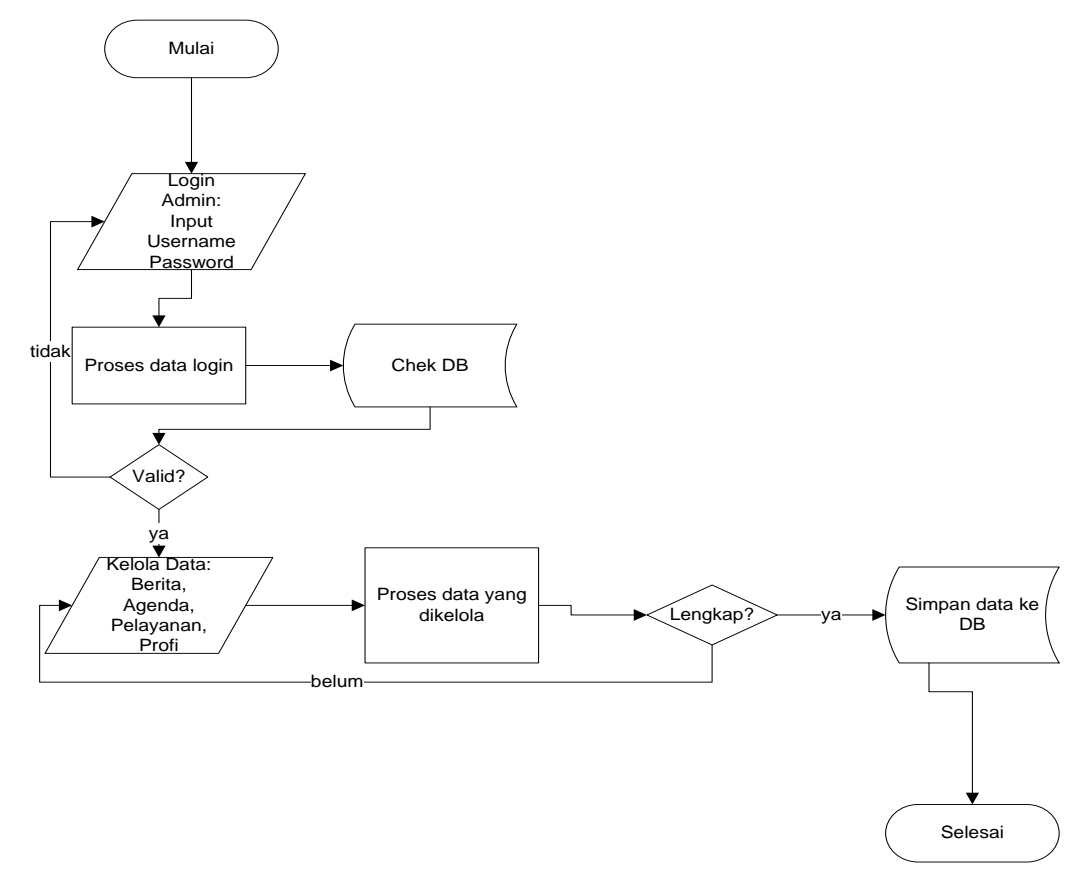

Gambar 2. Flowchart Sistem yang Diusulkan 


\subsubsection{Usecase Diagram Sistem}

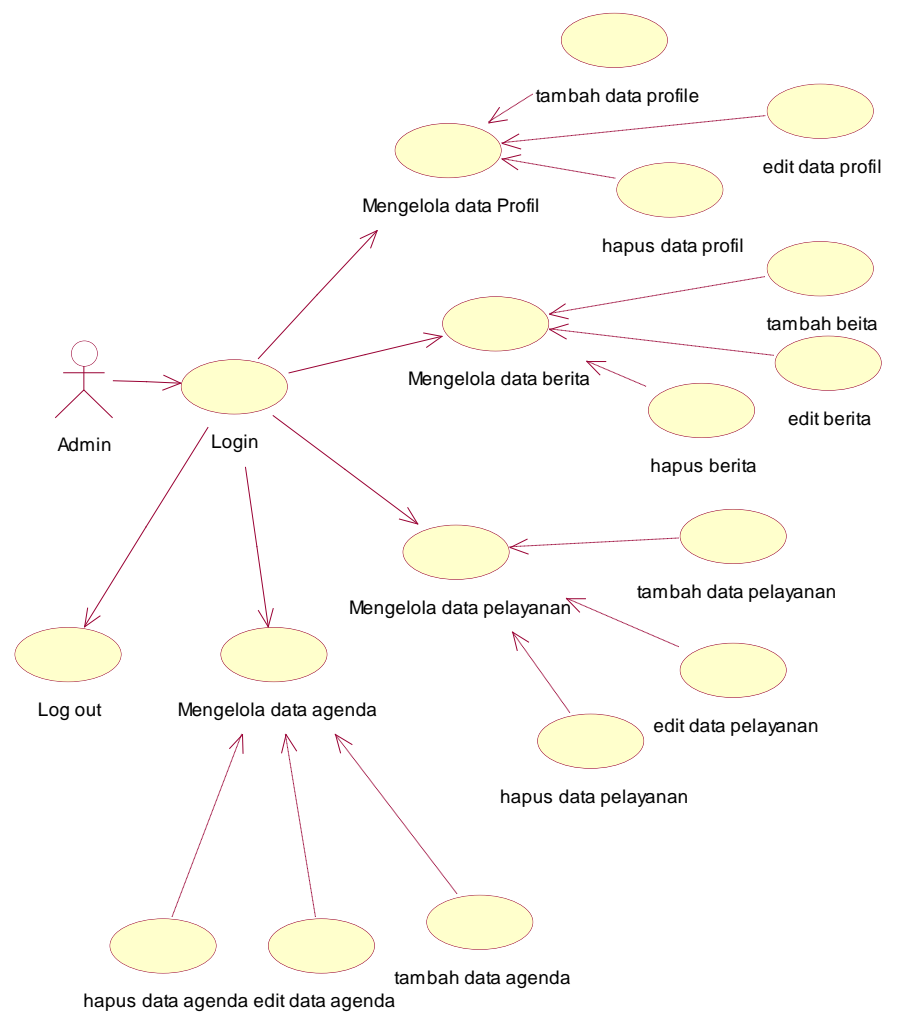

Gambar 3. Usecase Diagram Sistem

Gambar 3 menampilkan usecase diagram dari Sistem Informasi Pariwisata dan Kebudayaan ini. Terdapat 1 (satu) aktor dalam sistem ini yaitu admin yaitu anggota pada Komunitas terkait. Untuk memproses sistem, admin harus terlebih dahulu melakukan login. Setelah berhasil login, admin dapat melakukan kelola sistem diantaranya kelola data profil, berita, pelayanan dan agenda. Pada keempat menu kelola tersebut, admin dapat menerapkan 3 (tiga) fungsi yaitu tambah, ubah dan hapus. Setelah selesai mengelola sistem, admin dapat melakukan logout.

\section{Pembahasan Dan Hasil}

\subsection{Implementasi Sistem}

Implementasi sistem merupakan proses penerapan sekumpulan elemen yang telah dirancang menjadi sebuah program untuk menghasilkan suatu tujuan yang dibuat berdasarkan kebutuhan. Implementasi sistem perancangan Sistem Informasi Pariwisata dan Kebudayaan berbasis Website ini dilakukan dengan menggunakan bahasa pemograman php, untuk tampilan menggunakan perangkat lunak Adobe Dreamweaver CS6, perangkat local server dan database menggunakan xampp. Implementasi dan pengujian program menggunakan perangkat keras PC (Personal Computer) dengan blackbox testing. 


\subsection{Pembahasan Antarmuka Sistem}

Implementasi antarmuka sistem merupakan tampilan dari aplikasi yang telah dibuat. Berikut merupakan implementasi antarmuka perancangan sistem ini:

\subsubsection{Halaman Utama Sistem}

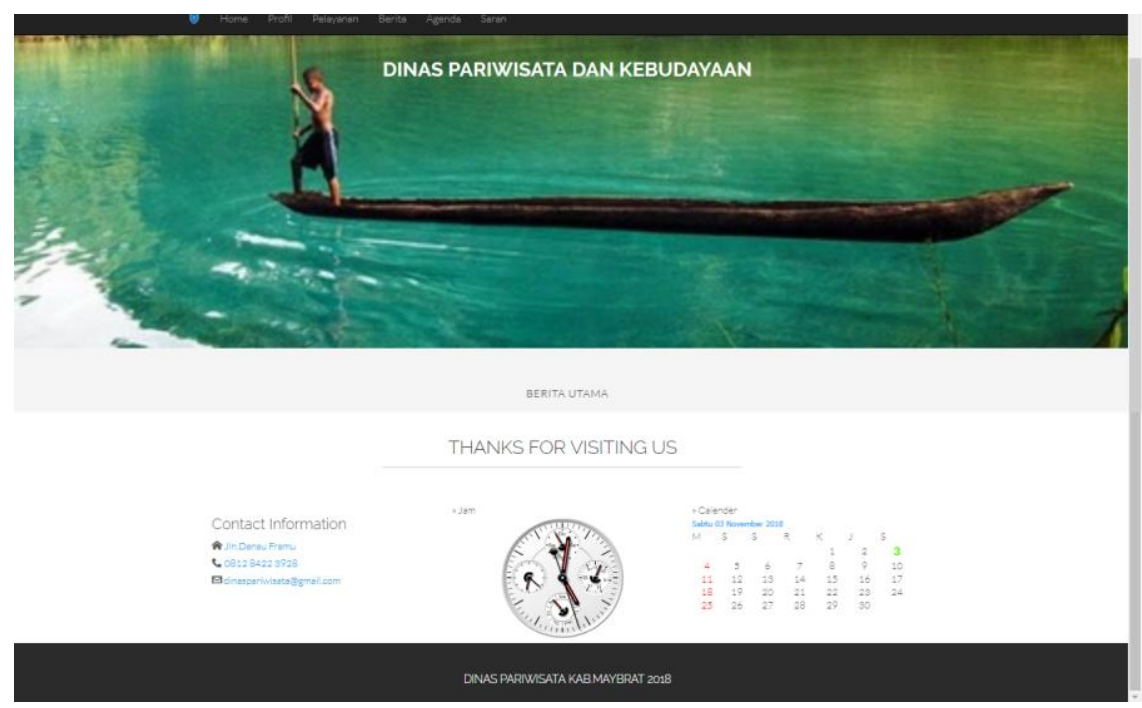

Gambar 4. Halaman Utama Sistem

Gambar 4 merupakan halaman utama sistem ini. Terdapat kolom banner adapula menu seperti home, profil, pelayanan, berita, agenda dan saran serta terdapat kolom berita utama, contact information, time dan calendar yang telah didesain dengan menarik.

\subsubsection{Halaman Profil Sistem}
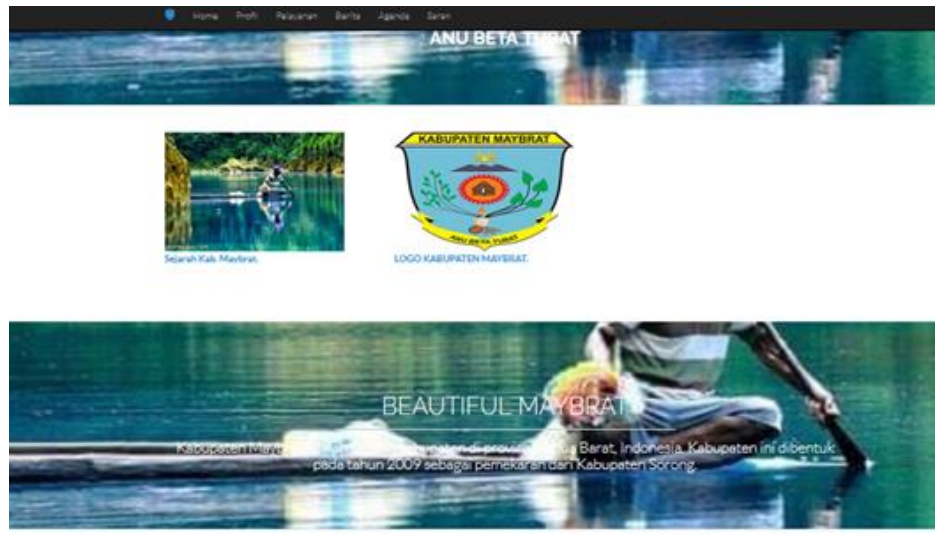

THANKS FOR VISITING US

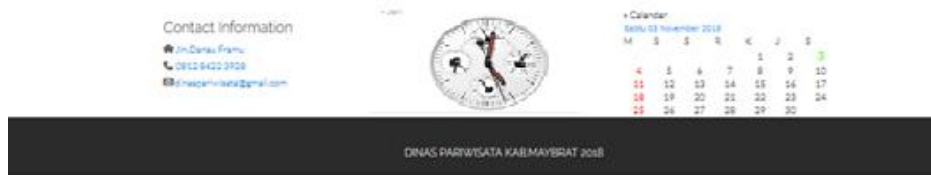

Gambar 5. Halaman Profil Sistem 
Gambar 5 merupakan halaman profil sistem. Terdapat kolom untuk mengisi data seperti sejarah, profil dan logo.

\subsubsection{Halaman Berita}

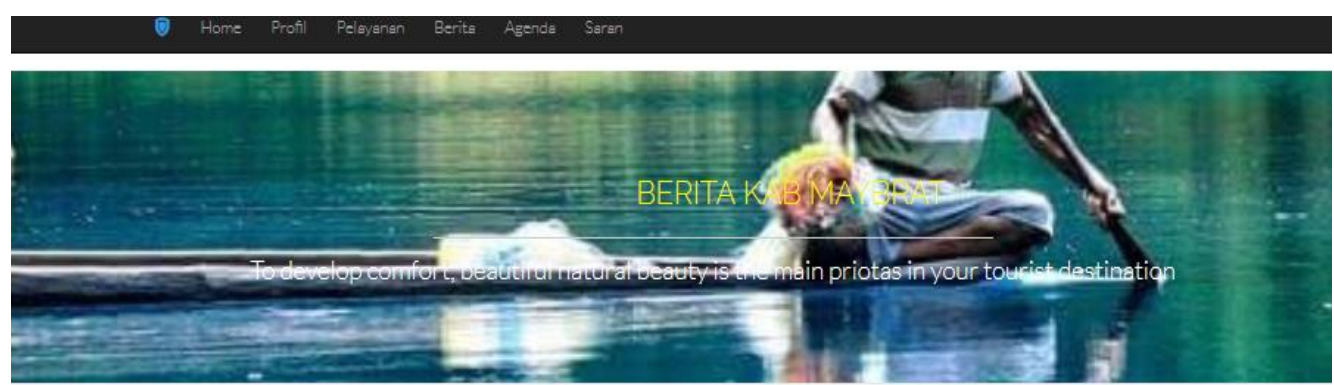

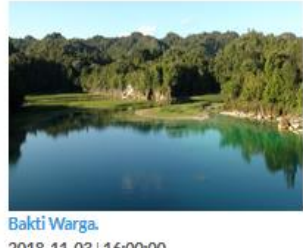

2018-11-03 | 16:00:00

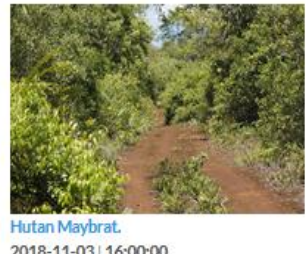

2018-11-03 | 16:00:00

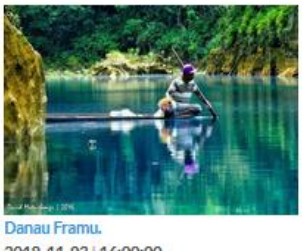

2018-11-03|16:00:00

Gambar 6 Halaman Berita

Gambar 6 merupakan tampilan halaman berita. Terdapat data seperti kegiatan-kegiatan yang telah dilakukan, dapat juga dimasukkan berita-berita yang sedang terjadi di Kabupaten Maybrat.

\subsubsection{Halaman Agenda}

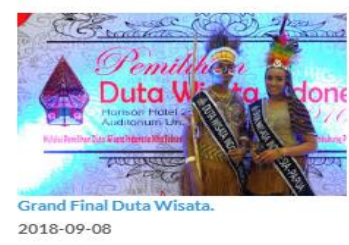

THANKS FOR VISITING US

Contact Information

ล $\ln$ Densu Framu

Ddinaspariwisata Ggmailcom
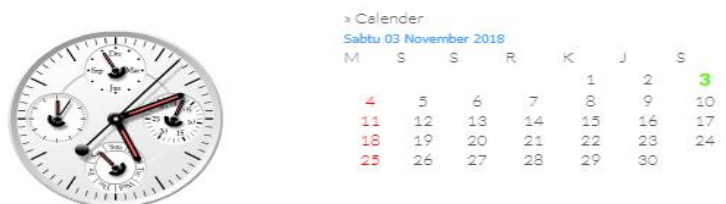

DINAS PARIWISATA KABMAYBRAT 2018

Gambar 7. Halaman Agenda

Gambar 7 merupakan tampilan halaman agenda. Terdapat data seperti jadwal-jadwal kegiatan tertentu ataupun agenda tertentu yang akan dilakukan di Kabupaten Maybrat. 


\subsubsection{Halaman Saran}

\section{THANKS FOR VISITING US}
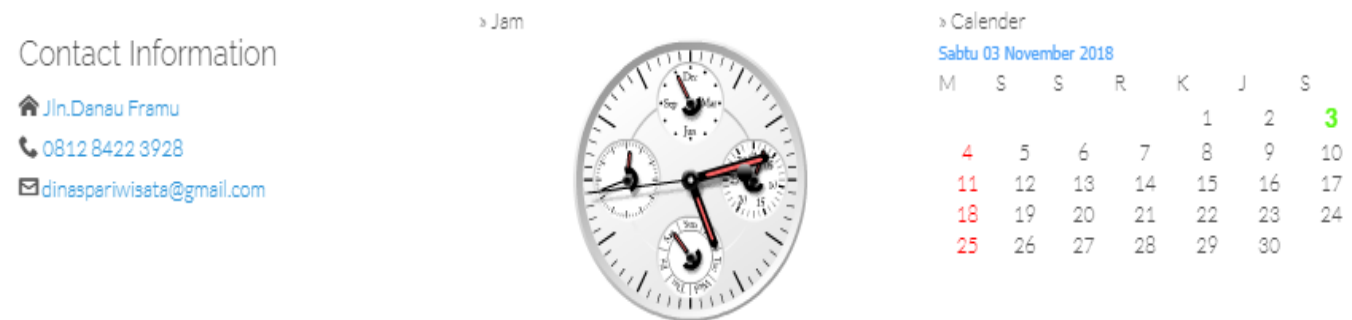

\section{DINAS PARIWISATA KAB.MAYBRAT 2018}

Gambar 8. Halaman Saran

Gambar 8 merupakan halaman saran dalam sistem. Terdapat kontak yang dapat digunakan untuk memperoleh informasi yang lebih banyak tentang pariwisata di Kabupaten Maybrat.

\subsubsection{Halaman Login Admin}

Gambar 9 merupakan tampilan halaman login admin. Terdapat kolom username dan password serta tombol login yang digunakan untuk masukan ke sistem.

\section{Login Ke Sistem}

\begin{tabular}{|l|}
\hline Username \\
\hline Password \\
\hline
\end{tabular}

Gambar 9. Halaman Login Admin

\subsubsection{Halaman Menu Utama Admin}

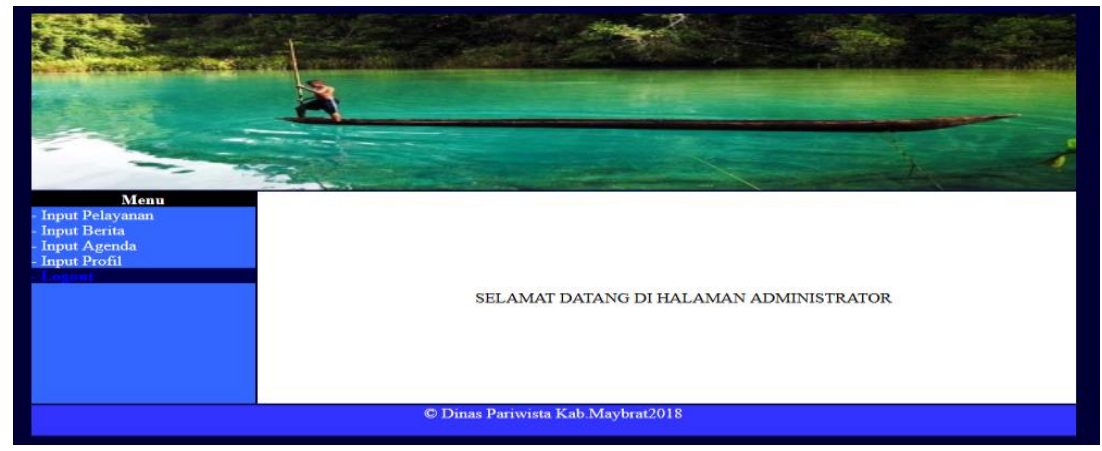

Gambar 10. Halaman Menu Utama Admin 
Gambar 10 merupakan tampilan halaman menu utama admin. Terdapat header dan footer sistem serta menu seperti pelayanan, berita, agenda dan profil.

\section{Kesimpulan Dan Saran}

\subsection{Kesimpulan}

Dari hasil penelitian yang telah dilakukan oleh peneliti, maka dapat disimpulkan beberapa hal sebagai berikut:

1. Sistem ini dapat membantu berbagai komunitas pecinta Pariwisata dan Kebudayaan dalam memberikan informasi pariwisata yang ada di Kabupaten Maybrat secara khusus.

2. Dengan menggunakan media website maka publikasi dari seluruh informasi pariwisata yang ada dapat dilakukan dengan efisien dan efektif, apabila terjadi perubahan-perubahan dapat lebih cepat diketahui oleh para pengunjung tanpa harus memakan waktu yang lama (pengunjung tidak terlambat untuk mengetahui perubahan - perubahan tersebut).

\subsection{Saran}

Berdasarkan hasil dari penelitian ini terkait pengembangan sistem informasi Pariwisata dan Kebudayaan Kabupaten Maybrat dan penelitian selanjutnya, sistem sebaiknya memerlukan tampilan peta dalam penentuan letak tempat wisata atau biasa disebut dengan Geography Information System (GIS), Memerlukan pengembangan dalam pencarian berdasarkan jenis informasi agar memudahkan pengunjung dalam mencari informasi tertentu, seperti informasi mengenai makanan, tempat wisata, atau kebudayaan, kemudian diperlukan pengembangan dalam melakukan validasi data yang dimasukkan oleh kontributor yang akan diatur oleh admin, serta menampilkan id kontributor yang mempublikasikan artikel pada website.

\section{DAFTAR REFERENSI}

[1] E. Turban, R. K. Rainer, dan R. E. Potter, Introduction to information technology. John Wiley \& Sons, (2005).

[2] J. A. O’Brien dan G. M. Marakas, Introduction to information systems, vol. 13. McGrawHill/Irwin New York City, USA, (2005).

[3] L. Al-Bahra, Analisis dan Desain Sistem Informasi. Yogyakarta: Graha Ilmu, (2005).

[4] H. M. Jogiyanto, Analisis dan desain sistem informasi. Yogyakarta: Andi, (2005).

[5] T. Sutabri, Analisis sistem informasi. Yogyakarta: Andi, (2012).

[6] T. Wahyono, Sistem Informasi (konsep dasar, analisis desain dan implementasi), vol. 150. Yogyakarta: Graha Ilmu, (2004).

[7] D. P. Wahyudi, Dasar-Dasar Teknik Komputer dan Informatika. Jakarta: Inti Prima Promosindo, (2012).

[8] D. M. Mertayasa dan A. R. Yambese, "Sistem Informasi Pariwisata Pantai Berbasis Web Pada Dinas Pariwisata dan Ekonomi Kreatif Kabupaten Banggai Kepulauan," Jurnal Elektronik Sistem Informasi dan Komputer, vol. 3, no. 1, hlm. 51-62, (2017).

[9] R. P. Ardhiyani dan H. Mulyono, "Analisis Dan Perancangan Sistem Informasi Pariwisata Berbasis Web Sebagai Media Promosi Pada Kabupaten Tebo," Jurnal Manajemen Sistem Informasi, vol. 3, no. 1, hlm. 952-972, (2018). 
[10] R. L. Baskerville dan M. D. Myers, "Information systems as a reference discipline," Mis Quarterly, hlm. 1-14, (2002).

[11] P. M. Ogedebe dan B. P. Jacob, "Software Prototyping: A Strategy to Use When User Lacks Data Processing Experience," ARPN Journal of Systems and Software, vol. 2, no. 4, (2012). 